\title{
An Investigation on the Performance of Random PWM Controlled Converters
}

\author{
Rajendrasinh Jadeja \\ Department of Electrical Engineering \\ Marwadi Education Foundation's \\ Group of Institutions \\ Rajkot, India \\ rajendrasinh.jadeja@ \\ marwadieducation.edu.in
}

\author{
Amit Dilipkumar Ved \\ Research Scholar, \\ School of Engineering, \\ R.K. University, Rajkot, India \\ amitved_1999@yahoo.co.uk
}

\author{
Siddharthsingh K. Chauhan \\ Department of Electrical Engineering \\ Marwadi Education Foundation's \\ Group of Institutions \\ Rajkot, India \\ siddharthsingh.chauhan@ \\ marwadieducation.edu.in
}

\begin{abstract}
This paper provides an insight on various random pulse width modulation techniques and their effect on spreading the harmonic spectrum for various applications like drives, hybrid electric vehicles and renewable energy sources, for two level as well as three level inverter. Acoustic noise reduction, electromagnetic interference conducted and torque ripple are obvious advantages of random pulse width modulation (PWM). PWM converters with multilevel topology can meet with global quality standards for power supplies. The random PWM technique provides additional advantages. Among others, it may be implemented to achieve switching loss equalization in power switches for cascaded $\mathbf{H}$-Bridge multilevel inverters. This paper provides in depth understanding for different random PWM techniques and their applications.
\end{abstract}

Keywords-Random PWM, Random SVPWM, Multilevel inverter, drives

\section{INTRODUCTION}

With the increased penetration of automation due to advancements in power semiconducting devices and processors like DSP, FPGA, CPLD etc., power electronic converters have found numerous applications in different fields. This has led to topological advancements in power electronic converters, with multi-level converter being one of them. Effective control of power electronic converters has emerged as a challenge. These converters use modulation techniques such as Selective Harmonic Elimination (SHE) or high switching frequency Pulse Width Modulation (PWM). SHE PWM technique utilizes a low frequency switching and hence can reduce switching losses. By selecting proper angles using advanced artificial intelligence techniques, it is possible to reduce lower order harmonics without affecting the fundamental component. However, this technique will also result to an increased switching frequency. For unbalanced load 3phase 4 leg neutral point clamped inverters the SHE PWM [1] and SHE pulse width amplitude modulation is proposed [2]. Selective harmonic mitigation (SHM) is combined with SHE to provide a better harmonic control [3]. However, SHE is limited to offline calculations and multicarrier techniques are also been worked upon [4]. Various PWM techniques have been implemented for the control of these converters.
PWM techniques are classified as Current Controlled PWM and Voltage Controlled PWM. These PWM techniques are also categorized as either carrier based or carrierless PWM schemes. For carrier based PWM schemes, a typical harmonics spectrum exhibits prominent harmonics around the carrier frequency. This results to the generation of acoustic noise at these frequencies by the machines controlled by such schemes. Also, it is better to have a distribution of harmonic energy over a wide frequency spectrum as compared to the energy being concentrated at few frequencies. This is achieved by carrierless PWM scheme.

Random PWM schemes also achieve spreading of the energy spectrum by randomly switching, random switching frequency and random pulse position [5]. For random PWM schemes research till now has mostly focus on a carrier based implementation. However, space vector (carrierless) based random PWM techniques which results in better DC bus voltage utilization and easier digital implementation is also gaining popularity. With increasing requirements of power electronic converter application at higher power levels (especially grid connected systems), implementation of multilevel converters is also continuously increasing. This paper is focused on investigating the performance for various random PWM schemes based two-level and multi-level inverter systems.

\section{DIFFERENT RANDOM PWM (RPWM) TECHNIQUES [6-45]}

Various PWM techniques are depicted in Figure 1. Acoustic switching noise gets remarkably reduced by increasing the carrier frequency above $18 \mathrm{kHz}$, however, that increases the switching losses in the inverter and decreases operating efficiency. An inverter with random PWM has an advantage of spread and continuously dispersed output harmonic spectra [6].

\section{A. Random Carrier Frequency (RCF-PWM) [7]}

The method is based on a random selection of the carrier frequency for each carrier period. The only requirement for RCF-PWM is to maintain the volt-second balance during a carrier period, ensuring that the fundamental frequency component is not affected by the randomization. 


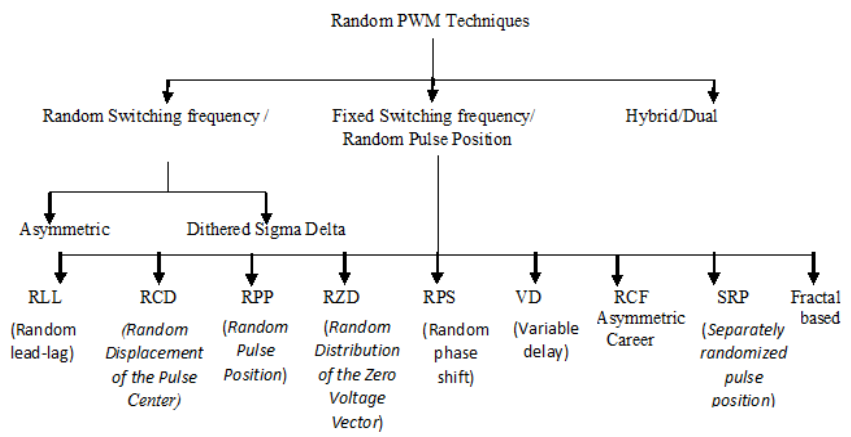

Fig. 1 Random PWM Techniques.

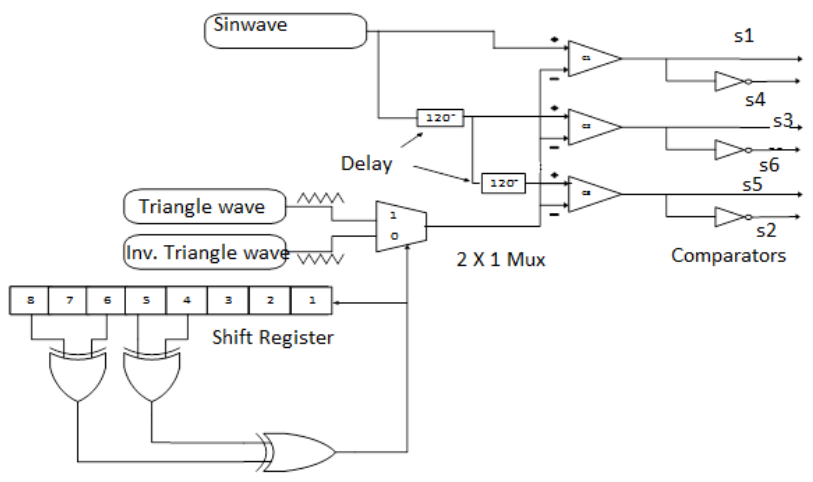

Fig. 2 Random Carrier Frequency PWM

The Random Carrier PWM technique uses two different triangular carriers as depicted in Figure 2. One is of required frequency and the other is 180 degree phase shifted. The selection of the carrier among these carriers is done by a random bit generated. That is, if ' 1 ' is the output carrier 1 (basic) is selected as carrier $2\left(180^{\circ}\right.$ shifted). The selection is done for ever carrier cycle and the selected carrier is compared with the reference sinusoidal waveform. The Pseudo random carrier modulation scheme is most commonly used for the random triangular frequency generation. Here, the random triangular frequency is achieved in the range of $3 \mathrm{kHz}$. Space vector based random carrier frequency scheme and switching pulse generation is shown in Figure 3
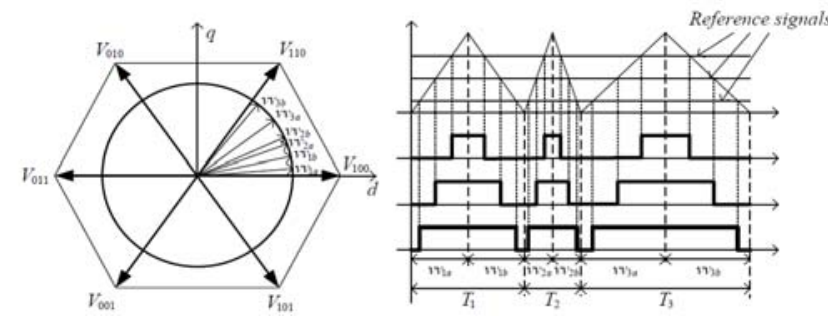

Fig. 3 Random Carrier frequency, SVM generated vector and switching pulse generation

\section{1) Random Switching Frequency (RSF) [8]}

Random switching frequency has a similarity with random pulse duration. Here the switching period is changed in every cycle and pulse period is placed at the beginning of switching cycle, i.e. the problem of randomization is minimized by randomly varying the switching period for a limited interval in the control loop as shown in Figure 4. A reference number or slope of triangular wave is varied in between a min and a max value randomly for all phases. However, it is difficult to select random frequency for real time applications,. In the majority of applications, sampling and PWM periods need to be synchronized. Random sample rate puts limitation on code size. Space vector based scheme requires either switching interval per cycle or sub cycle interval equivalent to 60 degrees are to be randomized. This applies a limitation on the interval for which frequency can be varied.

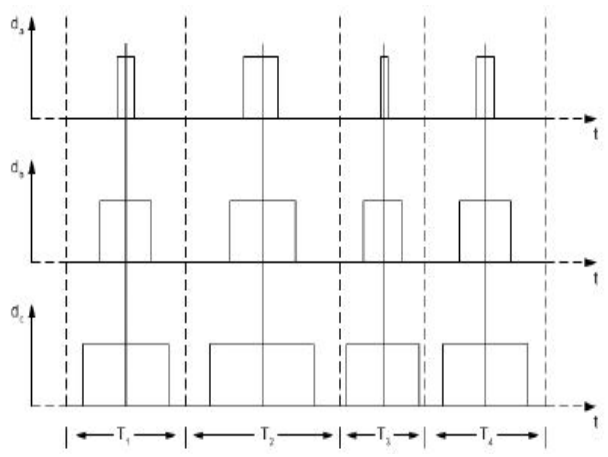

Fig. 4 Random switching frequency (RSF)

2) Dithered Sigma Delta Modulator (DSDM) based RPWM Switching Scheme [9-23]

Delta Sigma modulation is an oversampling method where sampling frequency is much above the frequency mentioned by Nyquist criteria. Here analog input is converted to digital output same as in an Analog to Digital Controller (ADC). As shown in Figure 5(a) the addition of a 1-bit random sequence to the LSB of the input signal, results in suppression of harmonic spikes in Dithered Sigma Delta Modulation (DSDM). The Dithered Sigma-Delta Modulation (DSDM) scheme has a Sigma Delta Modulator (SDM) and a random dither generator as component can be realized with simple hardware and software algorithms. As shown in Figure 5(b) random dither generation constitutes of random magnitude adjustment where in for every sampling period a random number is generated and subtracted by a bias as well as a sign discriminator which decides the application of dither [9]. There are two types of SDM, depending upon the position of random dither generator and quantizer viz. Space-Dither SDM (SDSDM). Space-Dither SDM (SDSDM) scheme employs quantizer being fed from a random dither generator in SDM while in Time-Dither SDM (TDSDM) the quantizer feeds the output to random dither generator. Harmonics spikes at multiples of switching frequency are reduced by using a sigma delta modulator where switching frequency is varied randomly using a vector quantization technique [10]. DSDM scheme is easy to implement due to less arithmetic operations and limited use of times. Harmonic Spread Factor is also 
comparable in the case of DSDM and RSVPWM [11-22]. A $2^{\text {nd }}$ ordered space dithered SDPWM is investigated in [23].

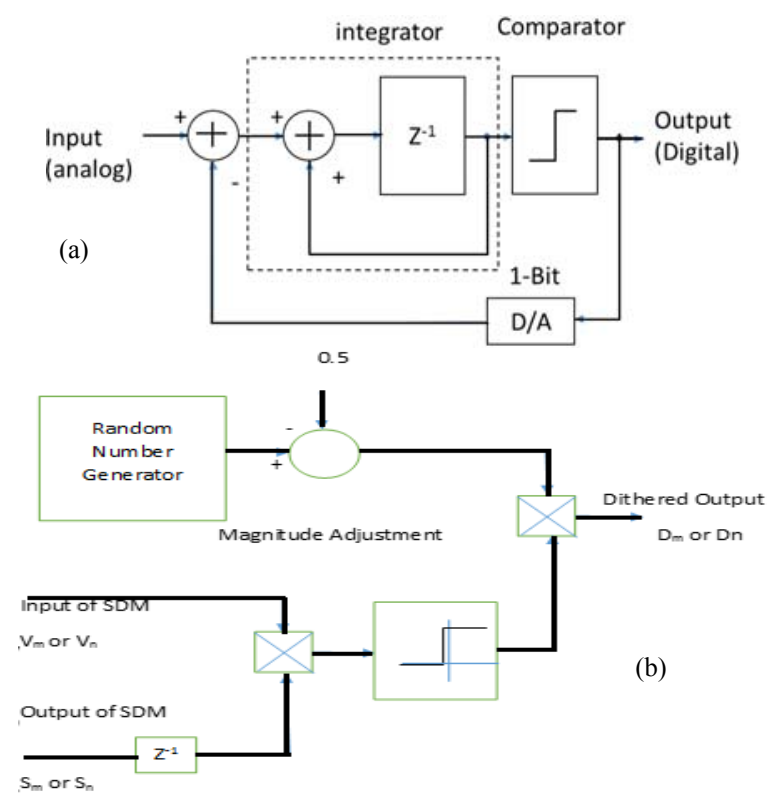

Fig 5. (a) Block diagram of SDM scheme, (b) Random Dither Generator

\section{B. Fixed Career frequency- Random PWM (FCF-RPWM) [24-38]}

In this method, the switching period is fixed and pulse position is varied randomly. These methods portray a good closed loop response. Figure 6 shows the control block of FCFRPWM which can be implemented with open loop or closed loop. Control block calculates the reference voltage vector in $\alpha \beta$ plane. SVM block will estimate and compare values for pwm. FF RPWM block will randomize active vectors and zero vectors $\overline{\text { in }}$ the given modulation period. Duty ratios are converted to compare values for generating random PWM output required by VSC block.

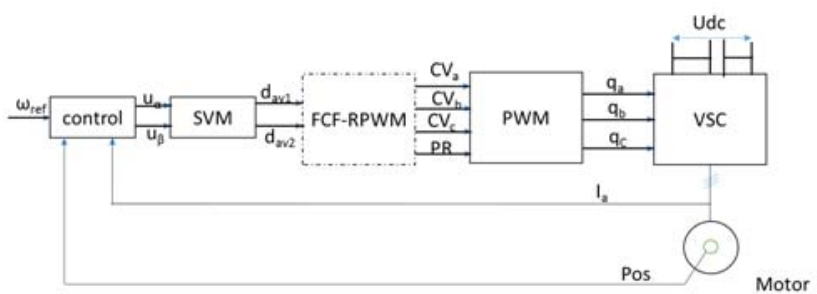

Fig. 6 FCF-RPWM in open \& Closed loop

The FCF-RPWM methods, even though easy to synchronize with the control algorithm suffer from problems like current sampling, calculation overhead and spreading effectiveness. The ollowing methods of FCF-RPWM are finding many applications in adjustable speed drives.

1)

Random Lead-Lag Modulation (RLL)[24-25]
With regular sampling, output cycle frequency is equally divided into equal switching intervals. At constant frequency the pulse position in all 3 phases, is either originating at the beginning of the switching interval (leading-edge modulation) or at its trailing edge (lagging-edge modulation) [24] as shown in Figure 7. Trailing edge modulated pulse width is used in lead mode, whereas leading-edge modulated pulse width is used in lag mode. Average switching frequency is decided to provide the optimum solution for switching losses as well as quality of output current. The random number generator decides leading and lagging edge modulation. Advantage of the scheme is a requirement of single bit random generator for randomization [25]. Sampling of current produces problems and use of anti-aliasing filter becomes necessary.

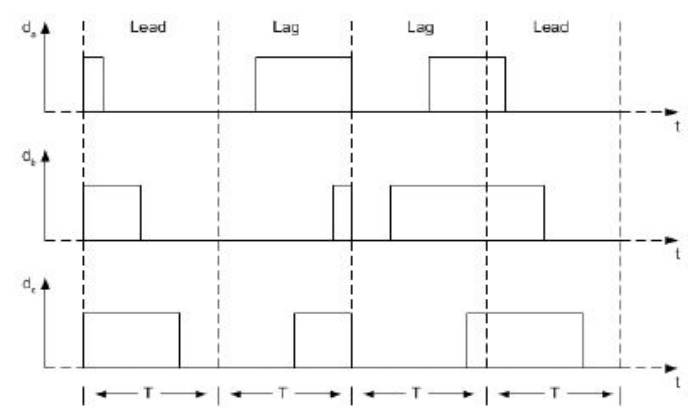

Fig. 7 Random lead-lag modulation (RLL)

2) Random Displacement of the Pulse Centre (RCD) [26]

In this method the pulses are mutually center-aligned at constant frequency as in space vector modulation (SVM), but the common pulse center is displaced by a small amount randomly (Trand1,) from the middle of the period [26]. At high (Modulation Index) MI values, displacement becomes very small. Variation of RCD PWM is available as the Dual Zero RCD, where for MI>0.8 (llllllll 111 is regarded as zero vector and for $\mathrm{MI}<0.8(000)$ is considered as zero vector. This helps to overcome issues with High MI values and provides randomization effect in a whole range of MI. Figure 8 shows PWM technique applied to two phase PWM.

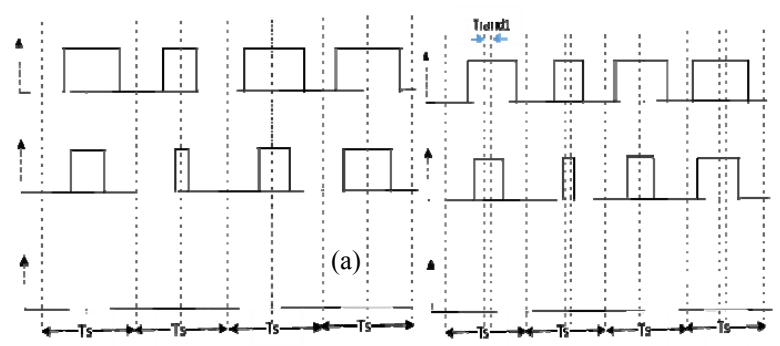

Fig. 8 (a) Centre Allign SVPWM (b) RCDPWM

3) Random Pulse Position PWM (RPP) [25-28]

The central idea is that the average output voltage over an interval is not dependent on pulse position. Methodology implements randomization of pulse position of one phase, pulse position of remaining phase is randomized as per previous 
phase in sequence. RPP PWM can be implemented by time intervals of zero states controlled randomly within a switching cycle. RLL is considered as a case of RPP. Here pulses can be placed anywhere randomly within switching interval [28]. RPP strategy cannot generate desired ideal noise spectra, though the harmonic clusters of power spectra for fixed switching intervals are less dominant and distributed in a better manner as compared to the deterministic vector PWM technique [25].

4) Random Distribution of the Zero Voltage Vector (RZD) [24]

Phase voltages are not altered by the duration of zero voltage vector in a three-phase, three-wire system. This point is employed in the random distribution of the zero voltage vectors at constant frequency. Random distribution of zero vectors limits maximum pulse change and becomes difficult at high MI values. Control strategy and required vector distribution are shown in Figure 9.

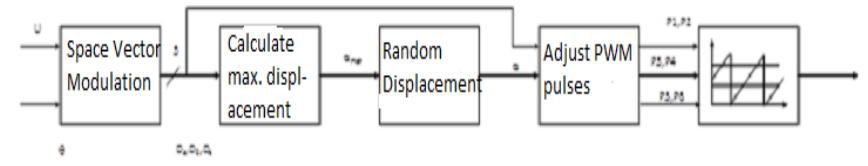

(a)

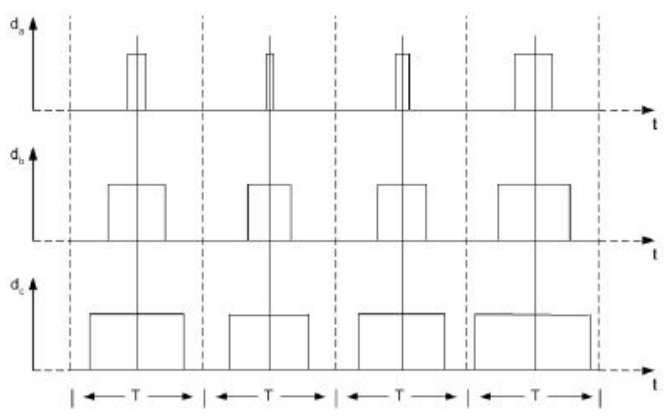

(b)

Fig. 9 (a). Random zero-vector distribution (b) Random zero-vector distribution

\section{5) Random Phase shift PWM (RPS)}

Here random phase shift time is applied randomly at constant frequency. Figure 10 shows RPS technique output waveform, where $t_{R P}$ is the Random Phase Shift time in the positive half-cycle, and $t_{\mathrm{RN}}$ is the Random Phase Shift time for the negative half-cycle. At each half cycle both $t_{R P}$ and $t_{R N}$ are altered randomly. In this method, the phase shift is varied randomly, keeping the switching frequency constant. For the RPS scheme, there is a random variation of phase shift keeping switching frequency constant. It has the advantage of reducing acoustic noise emissions generated by the PWM inverter. The phase shift of the fundamental component for each half-cycle controls, discrete harmonic components of the inverter output voltage.

6) Variable delay random PWM (VD-RPWM) [30]

In this method a random delay is introduced at the trailing edge of next PWM output cycle. Figure 11 shows the process for the calculation of switching time and random delay. Random delay is a product of sample period and the normalized random number. Obviously maximum delay will be produced with random number equal to 1 . Here switching period is varied randomly in between min switching period to double the value of sampling period that implements variable delay random PWM [30].

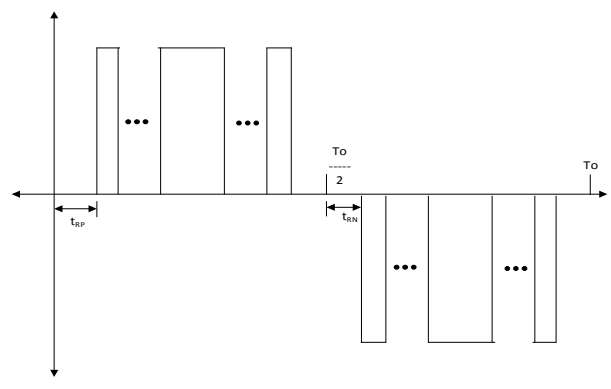

Fig. 10 Timing waveform of RPS scheme

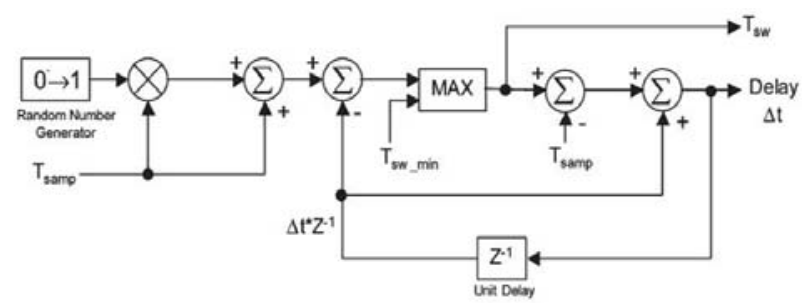

Fig. 11 Block diagram for computation of delays and switching period

7) Asymmetric Carrier Random PWM (AC-RPWM) [3132]

This scheme can be considered as a kind of RCF-PWM in which the new voltage vector is updated with a constant frequency. A different frequency is used to generate the voltage vector in the rising time period and falling time period. The scheme works well for both low and high MI values. The method selects a random time length for falling edge as well as rising edge for every modulation period, varying randomly time length of the active vector region as shown in Figure 12.

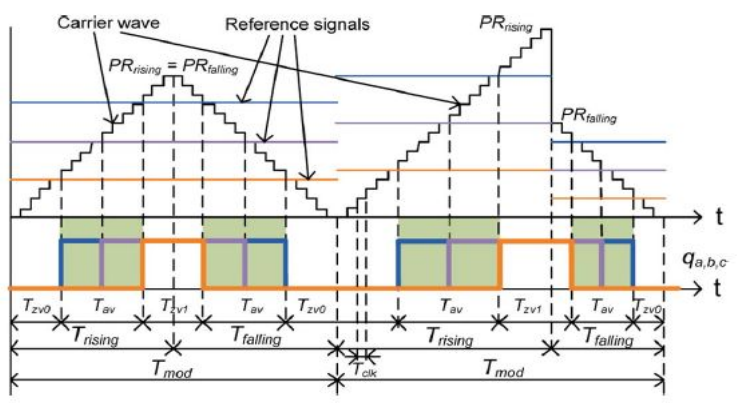

Fig. 12 AC-RPWM, 1st modulation time has symmetrical carrier and in 2nd modulation time it has asymmetric carrier

8) Separately randomized pulse position (SRP) [33]

Pulses are placed randomly in switching interval as shown in Figure 13. As there is full possibility to place pulse 
anywhere, a control for full range of MI is possible, as far as switching sequence is maintained. Calculation of duty ratio is done using space vector modulation, with each pulse located randomly. As pulse can be positioned randomly, harmonic spectrum is more flattened as compared to conventional methods. So, SVM based duty ratio calculation is followed by random positioning of pulse to realize SRP-PWM [33]

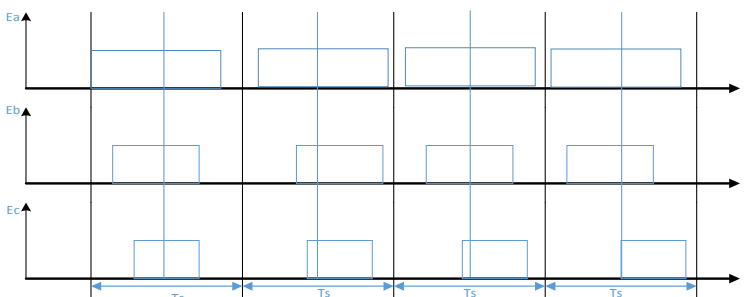

Fig. 13 SRP-PWM

\section{9) Fractal Based Space Vector PWM [34-38]}

Fractals are known as never ending patters made by repeating simple patterns by recursion and feedbacks. SVM representation of multi-level inverters have inherent fractal structure. Fractal approach can reduce the complexity in computation for sector identification and switching vector determination in SVPWM. The position of the reference vector in a given sector can be found by fractal methods. The basic pattern in the fractal base unit is a triangle comprised by three adjacent inverter voltage space vectors as shown in Figure 14 for 2-level, 3-level and 5-level inverter. In multilevel inverter, for higher level, each sector is divided into triangles and smaller sub triangles. Triangularization helps to implement this technique for any level of MLI [34]. For multi-level inverter, the number of sectors increases as the number of level increases. It is very complex to identify the location of reference vectors in the sector. 2-level inverter has 6 sectors, 3level inverter has 24 sectors. If we take $60^{\circ}$ coordinate system, fractal calculations can be avoided for 5-level inverter having 96 sectors [35-38]. The sector identification algorithm used in this method with reverse mapping technique does not require memory crunchy lookup tables. The inverter switching states for a sector are generated along with sector identification. This provides optimum switching of the vectors [35].
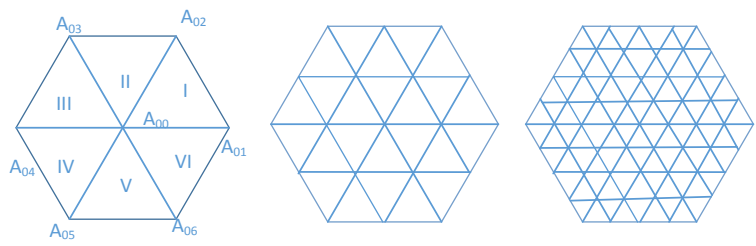

Fig. 14 2-level, 3-level and 5-level SVPWM

\section{Hybrid Random PWM or Dual Random PWM [39-43]}

With a view to gain advantage of better performance for the different Modulation Index (MI) values including over modulation region or to reduce the complexity of computation, the hybrid or dual random PWM methods are proposed. Here an attempt is made to maximize the advantages of various PWM schemes. A hybrid random PWM using dithered pulse position and zero vector position are suggested, simulated with complex calculations [39]. Hybrid scheme is also given by [40] using random pulse position and random career frequency PWM [5]. Lead lag random bit and random triangular carrier are used in [41-42]. Time for zero voltage is randomized to get better result with Direct Torque Control (DTC) for drives [43].

\section{Random SVPWM [44-45]}

SPWM converters have sideband harmonics and carrier acting as source of electromagnetic noise and pollution by common mode and differential mode noise. The Random PWM inverter has low weight, volume, filtering and has better EMI/EMC. Lower switching losses are useful to improve battery efficiency and reduced switching losses. SVM is digitally better implementable and has a higher output. Fixed frequency SVM also has high harmonics in switching frequency this can be spread by using random Space Vector PWM (RSVPWM). Three types of random SVPWM are suggested, random zero vector distribution PWM (RZDPWM), random pulse position PWM (RPPPWM) and random switching frequency PWM (RSFPWM) [44]. Mathematically random SVPWM is similar to traditional SVPWM and so existing methods for capacitor voltage balancing can be modified to reduce switching harmonics [45].

\section{RANDOM PWM CONTROLLED TWO -LEVEL INVERTERS} [46-59]

Output current of two-level inverters has a square wave with limited power range. It is rich with harmonics. The twolevel 3-phase Voltage Source Inverter (VSC) is considered as a mature technology and has become an industrial standard. The alternative topology to the VSC is the Current Source Converter (CSC), well suited for medium-voltage industrial applications with voltage waveforms having high quality required. Various authors have also implemented random PWM techniques for multilevel inverter, keeping methodologies adopted for 2-Level [46-58]. C. Guoqiang, W. Zhihong, Z. Yuan, and Z. Junwei realized Random Space Vector Pulse Width Modulation methods Based on Infineon Tricore TC1767/TC1797 like RSFPWM, RPPPWM, RZDPWM and Hybrid Random PWM is involving various combinations of three listed herewith [59]. The AC-RPWM technique is found appropriate for applications like heating, ventilation and air conditioning (HVAC) [31].

\section{RANDOM PWM CONTROLLED THREE-LEVEL INVERTERS [60-74]}

Multilevel inverters provide nearly sinusoidal output and achieve higher power output. This allows the use of renewable energy sources such as PV, wind, fuel cells to be easily interfaced with MLI for medium voltage, high power drives, distributed energy sources and Hybrid Electric Vehicles. Topology itself helps in reducing harmonics. Multilevel inverters are replacing conventional two-level inverters due to reduced $\mathrm{dv} / \mathrm{dt}$ stresses, common mode voltages, and lower harmonic distortion. 3-level RPWM in comparing to 2-level RPWM schemes has the advantages of low switching frequency, low continuous noise and low undesirable low-order 
harmonics, making it suitable for high voltage inverter application such as motor drives, active filters and power conditioning [60-62]. Different conventional topologies like Neutral Point clamped (NPC), cascaded H-bridge (CHB), and flying capacitor (FC) along with PWM strategies reported, are reviewed in [63]. Novel topologies are report for MLI in form of Crossover Switches Cell (CSC) for renewable energy sources and Pinned Mid-points Multilevel Inverter for high voltage applications [64-65]. In [60-61] the authors compared Random PWM technique for 2-level and 3-level. Their observations include that the fundamental component is found to be smaller in the 3-level RPWM scheme than in the 2-level RPWM scheme. Both 2-level and 3-level have a similar discrete spectral characteristic, however the 3-level has smaller continuous noise as compared to the 2-level. This advantage of the better power spectrum comes at the cost of a relatively higher switching frequency for specified sampling frequency [66]. T. Ramanathan et al. [67] utilized pseudo random carrier modulation technique for CHB MLI. Jacob and Baiju [65-66] applied Space Vector quantized DSDM technique for 3-level inverter to reduce harmonic noise to CHB MLI supplying power to induction motor drive. In [54] the authors implemented space vector based random PWM for 3-level inverter for any topology. In [50] the authors pointed out that the fixed frequency scheme has limitation in the form of the dependency of randomization on the duration of active vectors. In [70] the authors used combined DSDM based random PWM Scheme. Artificial intelligence tools like Fuzzy Logic, Genetic algorithm, etc., are also utilized to randomize the PWM output. In [71], the authors used clonal selection algorithm, a technique based on GA applied for 3-level PWM inverter for optimization. In [72], the authors implemented random frequency based Space vector PWM method and introduced wavelet transformation for better harmonic response. In [74], randomized-SVM application is also extended to Hybrid Electrical Vehicle (HEV).

\section{A. Applications of Random PWM [75-100]}

Random PWM finds extensive application in LV and MV Motor drives to reduce acoustic noise, electromagnetic interference, and harmonics at multiple of switching frequency, also it helps to flatten the power density spectrum [75-80]. Motor drives on board are increasing for electric, hybrid and fuel cell based vehicles. To decrease current ripple, switching loss and auto adjust to load characteristics along with other advantages very crucial for the consumer that is acoustic noise and electromagnetic noise make the random PWM better choice for application in automobiles [81-87]. Shunt Active Power filter is used to improve power quality issues like current harmonics and power factor for power system with nonlinear load. With random PWM, APF response can be improved without adding any cost [88-93]. Present scenario for inverter used with renewable energy sources: PWM techniques are used with MOSFET/IGBT while for high power SCR/GTO is required which can be controlled with suitable firing and commutation control. Another way by which we can use MOSFET/IGBT for medium or high power application is to go for Multilevel Inverter (MLI) [94-97]. Grid connected PWM converters used to control power for various applications including renewable energy sources are reported [99]. Use of SVPWM is reported in 3-Level NPC inverter [100].

\section{ANALYSIS OF RESEARCH WORK CARRIED OUT WITH RANDOM PWM AND RANDOM SVPWM}

Literature reveals the extensive usage of random PWM techniques in various applications. In order to further validate the research interest year by year refer to Figure 15. Figure 16 indicates that the research for random PWM is dominated by the field of drives, motor control and low power applications.

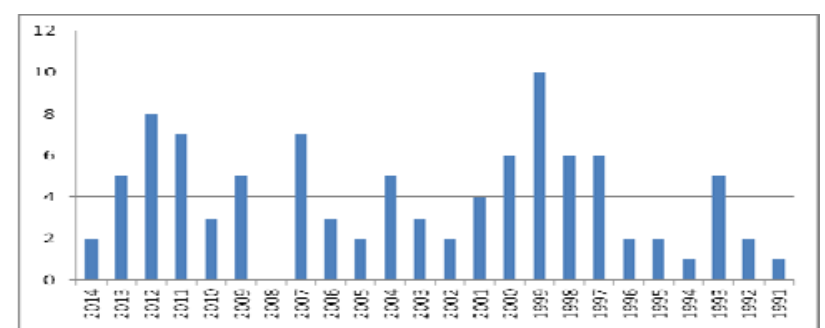

Fig 15. Papers published year wise for random PWM

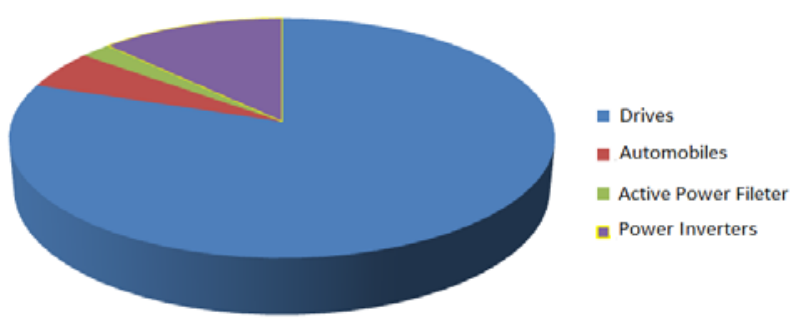

Fig. 16 Papers reporting random PWM

\section{CONCLUSION}

This paper presents a critical review of random PWM techniques and their applications. The random PWM technique is found to reduce harmonics in particular at a multiple of switching frequency. The technique has proved its advantages in drives especially through reduction of acoustic noise, mechanical vibration, torque ripple and current harmonics. The advantage of RPWM technique in reducing EMI conducted to the source is discussed. Drives, HEVs, active power filters have proved to provide better performance with the random PWM technique. Harmonic power remains unchanged with the randomizing technique, but can reduce the peaks at multiple of switching frequency and can reduce harmonic content in the current waveform. The effect of randomizing for inverters connected with renewable sources using bundled multilevel technique with the advantage of lower switching frequency, spreaded noise and low lower harmonics needs to be worked on, as renewable energy sources are preferred to address issues of pollution, energy security cost, etc. Hence there is a research gap for the issue of harmonic mitigation in grid connected systems by application of Random SVPWM technique for multilevel inverters. 


\section{REFERENCES}

[1] M. Sharifzade, H. Vahedi, A. Sheikholeslami, H. Ghoreishy, K. AlHaddad, "Selective Harmonic Elimination Modulation Technique Applied on Four-Leg NPC," in ISIE 2014-23rd IEEE International Symposium on Industrial Electronics, pp. 2163-2168, Turkey, 2014

[2] M. Sharifzade, H. Vahedi, A. Sheikholeslami, H. Ghoreyshi, K. AlHaddad, "Modified selective harmonic elimination employed in four-leg NPC inverters," in IECON 2014-40th Annual Conference of the IEEE Industrial Electronics Society, pp. 5196-5201, 2014

[3] M. Sharifzadeh, H. Vahedi, A. Sheikholeslami, P.-A. Labbé, K. AlHaddad, "Hybrid SHM-SHE Modulation Technique for Four-Leg NPC Inverter with DC Capacitors Self-Voltage-Balancing," IEEE Trans. Ind. Electron., Vol. 62, No. 8, pp. 4890-4899, 2015

[4] H. Vahedi, K. Al-Haddad, P.-A. Labbe, S. Rahmani, "Cascaded Multilevel Inverter with Multicarrier PWM Technique and Voltage Balancing Feature," in ISIE 2014-23rd IEEE International Symposium on Industrial Electronics, pp. 2151-2156, Turkey, 2014

[5] Y. C. Lim. "Shaping the Spectra of the Acoustic Noise Emitted by Three-Phase Inverter Drives based on the New Hybrid Random PWM Technique", $37^{\text {th }}$ IEEE Power Electronics Specialists Conference, pp. 16,2006

[6] I. A. Bakhovtsevand, A. K. Rakitin. "New PWM methods with deterministic change of carrier frequency", 2011 International Conference and Seminar on Micro/Nanotechnologies and Electron Devices Proceedings, pp. 406-410, 2011

[7] L. Mathe, Product Sound: Acoustically pleasant motor drives, $\mathrm{PhD}$ thesis, Department of Energy Technology, Aalborg University, 2010

[8] L. Solero. "Emission testing for the EMC performance evaluation of an electric wheelchair", International Symposium on Power Electronics Electrical Drives Automation and Motion 2006, pp. 597-602, 2006

[9] B. Jacob, M. R. Baiju. "Space vector based Dithered Sigma Delta Modulator for two-level inverter to suppress the harmonic spikes", 38th Annual Conference on IEEE Industrial Electronics Society, pp. 20052011, 2012

[10] H. Laaksonen, K. Kauhaniemi, "Voltage and current thd in microgrid with different dg unit and results system ," CIRED 2008: smart grid for Distribution, ,No. 57, pp. 23-24, 2008

[11] B. Jacob, M. R. Baiju, "Space Vector Quantized Dithered Sigma Delta Modulator for Reducing the Harmonic Noise in Multilevel Converters," IEEE Trans. Ind. Electron., Vol. 62, No. 4, pp. 2064-2072, 2014

[12] B. Jacob, M. R. Baiju, "Simple multilevel inverter-based induction motor drive scheme using sigma-delta converter with space-vector quantiser", IET Power Electronics, Vol. 5, No. 8, pp. 1483-1490, 2012

[13] J. D. Reiss. "Understanding sigma-delta modulation: the solved and unsolved issues," Journal of Audio Engineering Society,Vol. 56, No.1/2, pp. 49-64, 2008

[14] B. Jacob, M. R. Baiju. "Space Vector based Dithered Sigma Delta Modulator for two-level inverter to suppress the harmonic spikes", IEEE International Conference on Power Electronics, Drives and Energy Systems (PEDES), pp. 1-7, 2012

[15] B. Jacob, M. R. Baiju. "Spread spectrum modulation scheme for multilevel inverters using vector quantized sigma delta modulation." Twenty-Seventh Annual IEEE Applied Power Electronics Conference and Exposition (APEC), pp. 2428-2435, 2012

[16] B. Jacob, M. R. Baiju, "Space vector modulation scheme with direct Vector Quantization for any N-level voltage source inverter", 2012 IEEE Int. Conf. Power Electron. Drives Energy Syst., pp. 1-6, 2012

[17] B. Jacob, M. R. Baiju, "Vector quantized spread spectrum Pulse Density Modulation for four level inverters," IEEE Conf. Ind. Electron. Appl., pp. 674-679, 2011

[18] B. Jacob, M. R. Baiju, "Space Vector based Spread Spectrum Modulation scheme for three-level inverters," 2011 IEEE Appl. Power Electron. Colloq., Vol. 1, pp. 51-56, 2011

[19] B. Jacob, M. R. Baiju, "Spread spectrum modulation scheme for twolevel inverter using vector quantised space vector-based pulse density modulation,” IET Electr. Power Appl., Vol. 5, No. 7, pp. 589-596, 2011
[20] B. Jacob, M. R. Baiju. "Vector-Quantized Space-Vector-Based Spread Spectrum Modulation Scheme for Multilevel Inverters Using the Principle of Oversampling ADC", IEEE transactions on Industrial Electronics, Vol. 60, No. 8, pp. 2969-2977, 2013

[21] B. Jacob, M. R. Baiju. "Space-Vectored-Quantized Sigma-Delta Modulator for reducing the Harmonic Noise in Multilevel Converters." IEEE Transactions on Industrial Electronics Vol. 62, No. 8, pp. 20642072, 2015

[22] M. R. Baiju, B. Jacob, "A new Space Vector Modulation Scheme for any N-level Voltage Source Inverter which directly Quantizes the Reference Space Vector," 7th IET Int. Conf. Power Electron. Mach. Drives (PEMD 2014), pp. 1-6, 2014

[23] K. Chandra Shekhar, G. Tulasi Ram Das. "Five-level SPWM Inverter for an Induction Motor with Open end Windings", IEEE International Power and Energy Conference, pp.342-347, 2006

[24] S. - H. Kim, K. -B. Lee, "Elimination of harmonic spikes using secondorder Space Dithered Sigma-Delta Modulation." 13th European Conference on Power Electronics and Applications, (EPE '09), pp. 1-10, 2009

[25] M. M. Bech. "Random modulation techniques with fixed switching frequency for three phase power converters," IEEE Transactions on Power Electronics, Vol. 7, pp. 753-761, 2000

[26] A. M. Trzynadlowski, "Power spectra of a PWM inverter with randomized pulse position", IEEE Power Electronics Specialist Conference, pp. 1041-1047, 1993

[27] M. M. Bech, F. Blabjerg, J. K. Pedersen. "Random modulation techniques with fixed switching frequency for three-phase power converters", 30th Annual IEEE Power Electronics Specialists Conference Record, pp. 544-551, 1999

[28] S. Oh, Y. Jung, Y. Lim, “ A Two-Phase Dual-Zero Vector RCD-PWM (DZRCD)Technique." The 30th Annual Conference of the IEEE Industrial Electronics Society, pp. 30-34, 2004

[29] P. F. Leong. "Random Pulse-Width Modulated Neutral-Point-Clamped Inverter With Reduced Common-Mode Switching", International Conference on Power Electronics and Drives Systems, pp.1435-1440, 2005

[30] J. L. Shyu, T. J. Liang, J. F. Chen, "Digitally-controlled PWM inverter modulated by multi-random technique with fixed switching frequency", IEE Proceedings Electric Power Applications, pp.62-68, 2001

[31] S. E.Schulz, D. L. Kowalewski, "Implementation of Variable-Delay Random PWM for Automotive Applications", IEEE Transactions on Vehicular Technology, Vol.56, No. 3, pp. 1427-1433, 2007

[32] L. Mathe, F. Lungeanu, D. Sera, P. O. Rasmussen, J. K. Pedersen. "Spread Spectrum Modulation by Using Asymmetric- Carrier Random PWM", IEEE Transactions on Industrial Electronics, pp.3710-3718, 2012

[33] L. Mathe, F. Lungeanu, P. O. Rasmussen, J. K. Pedersen. "Asymmetric Carrier Random PWM", IEEE International Symposium on Industrial Electronics, pp.1218-1223, 2010

[34] Y. -C. Lim. "A new random PWM(SRP-PWM) technique for decreasing acoustic noise radiated from V/F controlled motor drives", 30th Annual Conference of IEEE Industrial Electronics Society, pp.832837,2004

[35] G. Shiny, M. R. Baiju, "A low computation Space Vector PWM scheme for multilevel inverters based on fractal approach," IEEE Symp. Ind. Electron. Appl., pp. 131-136, 2010

[36] M. R. Baiju. "Space Vector PWM for Multilevel Inverters - A Fractal Approach", 7th International Conference on Power Electronics and Drive Systems, pp.1230-1237, 2007

[37] G. Shiny, M. R. Baiju, "A Fractal based Space Vector PWM Scheme for General n-Level Inverters”, International Power Electronics Conference, pp. 847-854, 2010

[38] G. Shiny, M. R. Baiju, “A Space Vector Based Pulse Width Modulation Scheme for a 5-Level Induction Motor Drive", IEEE 9th International Conference on Power Electronics and Drive Systems (PEDS), pp. 292297,2011 
[39] G. Shiny, M. R. Baiju, "Space Vector based PWM scheme without sector identification for a 4-level dual inverter fed induction motor drive with asymmetrical DC link voltages", 25th Annual IEEE Applied Power Electronics Conference and Exposition (APEC), 2010, pp. 1963-1969.

[40] G. Chen, M. Zhang, and J. Zhao, "Harmonic Distortion Factor of A Hybrid Space Vector PWM Based on Random Zero-vector Distribution and Random Pulse Position,” Int. J. Adv. Inf. Sci. Serv. Sci., Vol. 4, No. 16, pp. 242-250, 2012

[41] K. -S. Kim, Y. -G. Jung, Y. -C. Lim, "A New Hybrid Random PWM Scheme", IEEE Transactions on Power Electronics, Vol.24, No. 1, pp. 192-200, 2009

[42] K. -S. Kim, Y. -G. Jung, Y. -C. Lim, "Shaping the Spectra of the Acoustic Noise Emitted by Three-Phase Inverter Drives based on the New Hybrid Random PWM Technique." $37^{\text {th }}$ IEEE Power Electronics Specialists Conference, pp. 1-6, 2006

[43] N. Boudjerda, A. Boudouda, M. Melit, B. Nekhoul, K. El Khamlichi Drissi, K. Kerroum. "Optimized dual randomized PWM technique for reducing conducted EMI in DC-AC converters.” EMC Europe 2011, pp. 701-706, 2011

[44] P. N. Reddy, J. Amarnath, P. L. Reddy. "Hybrid random PWM algorithm for direct torque controlled induction motor drive for reduced harmonic distortion", 2011 Annual IEEE India Conference (INDICON), pp. 1-5, 2011

[45] C. Hou, C. Shih, P. Cheng,, A. Hava, "Common-Mode Voltage Reduction pulse width Modulation Techniques for ThreePhase Grid Connected Converters", IEEE Transactions on Power Electronics, pp. 1971-1979, 2012

[46] Y. Shrivastava, C. K. Lee, S. Y. R. Hui, H. S. H. Chung, "Comparison of RPWM and PWM Space Vector Switching Schemes for 3-Level Power Inverters.” IEEE Power Electronic Specialist Conference, Vol. 1, pp. 138-145, 2001

[47] S. Xu, C. Chen. "Random PWM Technique Based Induction Motor Phase Current Reconstruction from DC-link Current of Inverters", 5th IEEE Conference on Industrial Electronics and Applications, pp. 749752,2010

[48] D. S. George, M. R. Baiju, "Random Pulse Width Modulation Technique for a 4-level Inverter," IEEE 7th International Power Engineering and Optimization Conference, Vol. 64, pp. 369-374, 2013

[49] M. R. Baiju, K. K. Mohapatra, V. T. Somasekhar, K. Gopakumar, L. Umanand, "A Five-Level Inverter Voltage Space Phasor Generation for an Open-end Winding Induction Motor Drive", IEE Proceedings Electric Power Applications, Vol. 150, No. 5, pp. 531-538, 2003

[50] D. S. George, M. R. Baiju, "Space Vector Based Random Pulse Width Modulation Scheme for a 3-level Inverter in Open-end Winding Induction Motor ConFiguration", IEEE International Symposium on Industrial Electronics (ISIE), Vol. 64, pp. 742-747, 2012

[51] V. Krishnakumar, V. Kamaraj, S. Jeevananthan, "Random Pulse Width Modulation Technique for Performance Improvement of Multilevel Inverter Brushless DC Motor Drive," Australian Journal of Basic and Applied Sciences, Vol. 9, No. 16, pp. 162-171, 2015

[52] D. S. George, M. R. Baiju, "Investigations on dependence of duration of active vectors on modulation index for inverters", IEEE International Symposium on Industrial Electronics, pp. 680-685, 2012

[53] D. S. George, M. R. Baiju. "Decoupled random modulation technique for an open-end winding induction motor based 3-level inverter." IEEE Symposium on Industrial Electronics \& Applications, Vol. 2, pp. 10221027, 2009

[54] D. S. George, M. R. Baiju. "Random PWM scheme for 3-level inverter using offset time randomization", 37th Annual Conference on IEEE Industrial Electronics Society, pp. 1989-1994, 2011

[55] I.A.Bakhovtsev, A. K. Rakitin. "New PWM methods with deterministic change of carrier frequency", International Conference and Seminar of Young Specialists on Micro/Nanotechnologies and Electron Devices (EDM), pp. 406-410, 2011

[56] K. Satyanarayana, J. Amarnath, A. K. Rao, "Two Random PWM Algorithms for Vector Controlled Induction Motor Drives with Low Computational Overhead and Fixed Switching Frequency", Acta Electrotechnica, Vol. 52, No. 1, pp. 18-24, 2011
[57] J. Chen "Design and Analysis of Low-Acoustic Noise Motor Drivers In Electric Machines and Drives", IEEE International Conference IEMDC '09, pp. 1188-1193, 2009

[58] B. M. Begum, T. B. Reddy, "Space Vector Based Random PWM Algorithms Based Direct Torque Controlled Induction Motor Drive." International Journal of Engineering Research and Applications, Vol.3, No. 5, pp. 754-760, 2013

[59] C. Guoqiang, W. Zhihong, Z. Yuan, Z. Junwei, "Realization of Random Space Vector Pulse Width Modulation Based on Infineon Tricore TC1767/TC1797”, Int. J. Digit. Content Technol. its Appl., Vol. 6, No. 20, pp. 624-632, 2012

[60] Y. Shrivastava, S. Y. R. Hui, "Analysis of random PWM switching methods for 3-level power inverters", 29th Annual IEEE Power Electronics Specialists Conference, pp. 1381-1387, 1998

[61] Y. Shrivastava, S. Y. R. Hui. "Analysis of Random PWM Switching Methods for Three-Level Power Inverters", IEEE Transactions on Power Electronics, Vol. 14, No. 6, pp. 1156-1163, 1999

[62] A. Gopinath, A. S. A. Mohammad, M. R. Baiju. "Fractal Based Space Vector PWM for Multilevel Inverters-A Novel Approach." IEEE Transactions on Power Electronics, Vol. 56, No. 4, pp. 1230-1237, 2009

[63] S. Kouro, M. Malinowski, K. Gopakumar, J. Pou, L. G. Franquelo, B. $\mathrm{Wu}$, J. Rodriguez, M. Pérez, J. Leon. "Recent advances and industrial applications of multilevel converters", IEEE Transactions on Industrial Electronics, Vol. 57, No. 8, pp. 2553-2580,

[64] H. Vahedi, K. Al-Haddad, Y. Ounejjar, K. Addoweesh "Crossover Switches Cell (CSC): A new multilevel inverter topology with maximum voltage levels and minimum DC sources", IECON 2013, 39th Annual Conference of the IEEE Industrial Electronics Society, pp.54-59, 2013

[65] H. Vahedi, S.Rahmani, K. Al- Haddad "Pinned mid-points multilevel inverter (PMP): Three-phase topology with high voltage levels and one bidirectionalswitch". Industrial Electronics Society, IECON 2013, 39th Annual Conference of the IEEE Industrial Electronics Society, pp.102107,2013

[66] Y. Shrivastava, S. Y. R. Hui, "Analysis of random PWM switching methods for 3-level power inverters", 29th Annual IEEE Power Electronics Specialists Conference, pp. 1381-1387, 1998

[67] T. Ramanathan, R. Ramesh, C. K. Subramaniam, K. Ganesan. "Pseudorandom Carrier based Subharmonic PWM for Cascaded Multilevel Inverters", IEEE International Symposium on Circuits and Systems (ISCAS), pp. 117-120, 2014

[68] B. Jacob, M.R.Baiju. "Harmonic noise reduction in three-level inverter using space vector based Dithered sigma Delta Modulator", 7th IET international conference on Power Electronics, Machines and Drives (PEMD 2014), pp. 1-6, 2014

[69] B. Jacob, M. R. Baiju, "Space Vector Quantized Dithered Sigma Delta Modulator for Reducing the Harmonic Noise in Multilevel Converters", IEEE Trans. Ind. Electron., Vol. 62, No. 4, pp. 2064-2072, 2015

[70] S. H. Kim, W. Choi, S, Choi, K. B. Lee, "Combined dithered sigmadelta modulation based random PWM switching scheme", Journal of Power Electronics, Vol. 9, No. 5, pp. 667-678, 2009

[71] H. Lou, C. Mao, D, Wang, J. Lu, "PWM optimisation for three-level voltage inverter based on clonal selection algorithm", IET Electric Power Applications, Vol.1, No. 6, pp. 870-878, 2007

[72] R. Adlakha, P. R. Sharma, "Space vector modulation for two level and three level vsi and comparison with wavelet", 4th International Conference, New Delhi, India , pp. 57-62, 2013 (available at: http://iraj.in/iraj_proc.php?id=31)

[73] H.Khan, E. Miliani, H. Ouzaarou, K. E. K. Drissi. "Random discontinuous space vector modulation for variable speed drives." IEEE International Conference on Industrial Technology (ICIT), pp. 985-990, 2012

[74] H. Khan, Y. Touzani, K. E. K. Drissi, "Random space vector modulation for electric drives: A digital approach",. 14th Int. Power Electron. Motion Control Conf. EPE-PEMC 2010, No. 3, pp. 20-24, 2010

[75] H. Khan, E. Miliani, K. E. K. Drissi, "Discontinuous Random Space Vector Modulation for Electric Drives: A Digital Approach," IEEE Trans. Power Electron., Vol. 27, No. 12, pp. 4944-4951, 2012 
[76] M. Lane, D. Ashari, F. Gu, A. Ball, "Investigfation of Motor Current Signature Analysis in Detecting Unbalanced Motor Windings of an Induction Motor with Sensorless Vector Control Drive", Vibration Engineering and Technology of Machinery, pp. 801- 810, 2015

[77] R. L. Kirlin, S. Kwok, S. Legowski, A. M. Trzynadlowski, "Power spectra of a PWM inverter with randomized pulse position", IEEE Transactions on Power Electronics, Vol. 6, No. 5, pp. 463-472, 1994

[78] R. Burkart, J. W. Kolar, "Overview and Comparison of Grid Harmonics and Conducted EMI Standards for LV Converters Connected to the MV Distribution," 1st Power Electronics South America 2012 Conference and Exhibition (PCIM 2012), South America, Saõ Paulo, Brazil, pp. 1-9, September 11-13, 2012

[79] R. Kirlin, S. F. Legowski, A. M. Trzynadlowski. "An optimal approach to random pulse width modulation in power inverters," 26th Annual IEEE Power Electronics Specialists Conference, pp. 313-318, 1995

[80] R. L. Kirlin, C. Lascu, A. M. Trzynadlowski. "Shaping the Noise Spectrum in Power Electronic Converters." IEEE Transactions on Industrial Electronics, Vol. 58, No. 7, pp. 2780-2788, 2011

[81] R. L. Kirlin, M. M. Bech, A. M. Trzynadlowski. "Analysis of power and power spectral density in PWM inverters with randomized switching frequency", IEEE Transactions on Industrial Electronics, Vol.49, No. 2 , pp. 486-499, 2002

[82] R. L. Kirlin, M. M. Bech, A. M. Trzynadlowski. "Power spectral density analysis of randomly switched pulse width modulation for DC/AC converters", 10th IEEE Workshop on Statistical Signal and Array Processing, pp. 373-377, 2000

[83] R. L. Kirlin, M. M. Bech, A. M. Trzynadlowski, B. Huo. "Power and power spectral density in PWM inverters with randomized switching frequency." 32nd Annual Power Electronics Specialists Conference, pp. 188-192, 2001

[84] R. L. Kirlin, S. Kwok, S. Legowski, A.M. Trzynadlowski. "Power spectra of a PWM inverter with randomized pulse position", 24th Annual IEEE Power Electronics Specialists Conference, pp. 1041-1047, 1993

[85] A. Napoli, A. D. Lidozzi, L. Solero, "Comparison of Random Modulation Techniques for EMI Reduction in Electric Vehicles", Proceedings of SPEEDAM , pp. 488-493, 2004

[86] Z. Wang, K. T.. Chau, M. Cheng, "A Chaotic PWM Motor Drive for Electric Propulsion", IEEE Vehicle Power and Propulsion Conference (VPPC), pp. 3-8, 2008

[87] S. E.Schulz, D. L. Kowalewski, "Implementation of Variable-Delay Random PWM for Automotive Applications", IEEE Transaction on Vehicular Technology, Vol. 56, No. 3, pp. 1427-1433, 2007

[88] K. Borisov, A. M. Trzynadlowski. "Experimental investigation of a naval propulsion drive model with PWM-based attenuation of the acoustic and electromagnetic noise", 29th Annual Conference of the IEEE Industrial Electronics Society, Vol. 1, pp. 12-17, 2003

[89] K. Borisov, H. Ginn, A. M. Trzynadlowski, "Mitigation of Electromagnetic Noise in a Shunt Active Power Filter Using Random PWM", 33rd Annual Conference of the IEEE Industrial Electronics Society, pp. 1886-1891, 2007

[90] K. Borisov, H. L. Ginn, A. M. Trzynadlowski, "Attenuation of Electromagnetic Interference in a Shunt Active Power Filter", IEEE Transactions on Power Electronics, Vol. 22, No. 5, pp. 1912-1918, 2007

[91] A. Esmaeli, M. Mobini. "Research and Development Random pulse width modulation", International Research Journal of Applied and Basic Sciences, Vol. 6, No. 9, pp. 1243-1248, 2013

[92] A. Esmaeli, Z. Kohshari, "Application of Random PWM Technique for Reducing EMI", International Research Journal of Applied and Basic Sciences, Vol.6, No. 9, pp. 1237-1242, 2013

[93] S. Kaboli, J. Mahdavi, A. Agah, "Application of Random PWM Technique for Reducing the Conducted Electromagnetic Emissions in Active Filters", IEEE Transactions on Industrial Electronics, Vol.54, No. 4, pp. 2333-2343, 2007

[94] D. M. Scholten, N. Ertugru, W. L. Soong, "Micro-Inverters in Small Scale PV Systems: A Review and Future Directions", Australasian Universities Power Engineering Conference, pp. 1-6, 2013
[95] H. Patel, V. Agarwal. "MPPT Scheme for a PV-Fed Single-Phase GridConnected Inverter Operating in CCM With Only One Current Sensor." IEEE Transaction on Energy Conversion,Vol.24, No. 1, pp. 256-263, 2009

[96] S. Verma, H. K. Verma, M. K. Mohiddin, "Modeling \& Analysis Of Standalone Photovoltaic System", International Journal of Research in Engineering and Technology, Vol.2, No. 11, pp. 259-265, 2013

[97] N. D. Marks, T. J. Summers, R. E. Betz, "Photovoltaic Power Systems: A Review of Topologies, Converters and Controls", 22nd Australasian Universities Power Engineering Conference (AUPEC), pp. 1-9, 2012

[98] G. Satheesh, T. B. Reddy, C. Saibabu, "A Family of Random PWM Algorithms for Reduction of Torque Ripple and Current Harmonics of Direct Torque Controlled Open End Winding Induction Motor", Journal of Control, Automation and Electric Ease of Use, pp.349-357, 2014

[99] T. A. Trivedi, R. Jadeja, P. Bhatt. "A Review on Direct Power Control for Applications to Grid Connected PWM Converters", Engineering, Technology \& Applied Science Research, Vol. 5, No. 4, pp. 841-849, 2015

[100] M. K .Sahu, A. K. Panda, B. P. Panigrahi. "Direct Torque Control for Three-Level Neutral Point Clamped Inverter-Fed Induction Motor Drive.” Engineering, Technology \& Applied Science Research, Vol. 2, No. 1, pp. 201-208, 2012 